\title{
Prevalence of hyperglycemia in pregnancy and influence of body fat on development of hyperglycemia in pregnancy among pregnant women in urban areas of Arusha region, Tanzania
}

Safiness Simon Msollo ${ }^{1,2^{*}}$ D, Haikael David Martin ${ }^{1}$, Akwilina Wendelin Mwanri ${ }^{2}$ and Pammla Petrucka ${ }^{3}$

\begin{abstract}
Background: Hyperglycemia in pregnancy is a medical condition resulting from either pre-existing diabetes or insulin resistance developed during pregnancy. This study aimed to determine the prevalence of hyperglycemia in pregnancy and influence of body fat percentage and other determinants on developing hyperglycemia in pregnancy among women in Arusha District, Tanzania.

Methods: A cross-sectional study was conducted between March and December 2018 at selected health facilities in Arusha District involving 468 pregnant women who were not known to have diabetes before pregnancy. Blood glucose was tested by Gluco-Plus ${ }^{\mathrm{TM}}$ using the World Health Organization criteria at fasting and $2 \mathrm{~h}$ after consuming $75 \mathrm{~g}$ of glucose dissolved in $300 \mathrm{ml}$ of water. Body fat was measured using a bioelectric impedance analyzer, midupper arm circumference using a regulated tape, weight using SECA ${ }^{\mathrm{TM}}$, blood pressure using a GT-868UF Geratherm ${ }^{\mathrm{TM}}$ machine, and height using a stadiometer. Demographic and maternal characteristics were collected through face to face interviews using a structured questionnaire.

Results: The participants' mean age was 28 years (SD \pm 6 ), mid-upper arm circumference $27 \mathrm{~cm}(S D \pm 3.7)$, body fat $33.72 \%$ (SD \pm 7.2$)$ and pre-pregnancy body mass index $25.6 \mathrm{~kg} / \mathrm{m}^{2}(\mathrm{SD} \pm 5.5)$. One-third of participants had midupper arm circumferences $\geq 28 \mathrm{~cm}$ with $25 \%$ being overweight and $22.7 \%$ obese before pregnancy. Prevalence of hyperglycemia in pregnancy was $16.2 \%(n=76)$ of which $13 \%$ had gestational diabetes and $3.2 \%$ diabetes in pregnancy. Hyperglycemia in pregnancy was significantly associated with body fat percentage (AOR 1.33; 95\% Cl: 1.22-1.44), family history of Type 2 diabetes mellitus (AOR $6.95,95 \% \mathrm{Cl}: 3.11-15.55$ ), previous delivery of babies $\geq 4$ kg (AOR 2.3, 95\% Cl: 1.00-5.28), mid-upper arm circumference $\geq 28 \mathrm{~cm}$ (AOR 1.2, 95\% Cl: 1.09-1.32), and Type 2 diabetes mellitus symptoms (AOR 2.83, 95\% Cl: 1.53-6.92).

Conclusion: The prevalence of hyperglycemia in pregnancy was high, particularly among women with history of delivering $\geq 4-\mathrm{kg}$ babies, increased body fat, mid-upper arm circumference, symptoms and/or family history of Type 2 diabetes mellitus. These findings identify opportunities to further explore the utility of body fat percentage and other determinants for rapid screening and management of hyperglycemia in pregnancy.
\end{abstract}

Keywords: Hyperglycemia in pregnancy, Body fat, Risk factors, Arusha, Tanzania

\footnotetext{
* Correspondence: msollos@nm-aist.ac.tz

${ }^{1}$ Department of Food Biotechnology and Nutritional Sciences in School of

Life Sciences, Nelson Mandela African Institution of Science and Technology,

P. O. Box 477, Arusha, Tanzania

${ }^{2}$ Department of Food Technology, Nutrition and Consumer Sciences,

Sokoine University of Agriculture, Morogoro, Tanzania

Full list of author information is available at the end of the article
}

(C) The Author(s). 2019 Open Access This article is distributed under the terms of the Creative Commons Attribution 4.0 International License (http://creativecommons.org/licenses/by/4.0/), which permits unrestricted use, distribution, and

reproduction in any medium, provided you give appropriate credit to the original author(s) and the source, provide a link to the Creative Commons license, and indicate if changes were made. The Creative Commons Public Domain Dedication waiver (http://creativecommons.org/publicdomain/zero/1.0/) applies to the data made available in this article, unless otherwise stated. 


\section{Background}

Hyperglycemia in pregnancy (HIP) is one of the most common pregnancy-specific health challenges [1]. Hyperglycemia first detected at any time during pregnancy should be classified either as diabetes mellitus in pregnancy (DIP) or gestational diabetes mellitus (GDM). Hence, HIP is a result of either pre-existing diabetes or insulin resistance developed during pregnancy, a condition known as gestational diabetes mellitus (GDM) which is defined as impaired glucose tolerance first recognized during pregnancy [2-4]. This condition occurs due to pregnancy-induced changes in maternal glucose metabolism and insulin sensitivity, whereby demand for insulin production on the mother's pancreas increases as the pregnancy proceeds [5]. In most instances, these women can meet the increased insulin demand, but failure to accommodate results in poor glycemic control. This condition may disappear spontaneously after delivery, but, if misdiagnosed and mismanaged, may lead to persistent long-term health risks to the mother and the child, such as predisposition to obesity and development of Type 2 diabetes mellitus (T2DM) within five to 10 years postpartum [6].

Globally, the prevalence of GDM among women aged 20-49 years was estimated to be $17 \%$ affecting 21.4 million live births with more than $90 \%$ cases occurring in low- and middle-income countries [6]. Estimates suggest that GDM ranges between 6 and 18\% in East and West Africa with pockets of higher prevalence (i.e., 19.5\% in urban areas of Tanzania) [7, 8]. Inaction on the HIP agenda will lead to future high prevalence and contribute to an increased disease burden on the health system. Considering the disproportionate rates of overweight/ obesity among Tanzanian pre-pregnant women in urban (42\%) and rural (21\%) locations, localized considerations are required [9]. Women with hyperglycemia are at high risk of hypertension, abortion/miscarriage, and/or a pregnancy resulting in a newborn who is large for gestational age (macrosomia), preterm birth, and/or incur perinatal death [10]. A number of risk factors contributing to HIP include family history of DM, previous delivery to macrosomia or stillbirth, intrauterine fetal death (IUFD), maternal obesity, and preterm delivery [11].

In addition to sedentary lifestyle, maternal height, dietary factors, cigarette smoking, and extreme pregnancy weight gain accompanied by high body fat accumulation place women at risk of HIP. Body fat percentage can alter body composition leading to pregnancy diabetes and other complications, such as pregnancy induced hypertension and predisposition of the newborn to overweight later in life [12-14]. It can also affect growth of the fetus; therefore, assessment of change in body fat content is important as predictive of both maternal and child health [15]. Body mass index (BMI) is a commonly used standard measure for assessing body fatness [16]; however, it does not distinguish between fat and lean body mass [17]. The delay of onset of antenatal care (ANC) means most women do not know their pre-pregnancy weight which makes it difficult to estimate BMI and weight gain during pregnancy which is reported to be strongly correlated with fat mass change [18]. This pre-pregnancy metric is even more important because, in addition to body fat and lean body mass, the fetal mass and amniotic fluid constitute an unknown contribution to total body mass of the mother which is indistinguishable within the BMI calculation. Furthermore, women, who are not obese by traditional weight criteria, may have an increased percentage of body fat distributed predominantly in the abdominal region, which leads to increased risk of HIP [19]. Studies done with T2DM patients have identified that fat deposits within skeletal muscle and liver cells is a major contributing factor to insulin resistance; however, there is lack of evidence on whether fat deposition during pregnancy adequately explains the acquisition of insulin resistance as a marker for HIP [20, 21].

Few studies have assessed the effects of body fat on development of GDM with most extant studies considering Caucasian and Asian populations [22, 23]. This variance requires redress as risks for HIP differ across ethnic, geographic, and genetic lines due to differences in body composition, lifestyles, genetic susceptibility, as well as healthcare system capacities [24]. Some populations may have lower BMI but high rates of HIP. For example, Asian populations tend to have a lower BMI, but accumulate visceral fat and develop abdominal obesity [25] which is positively associated with insulin resistance and impaired $\beta$ cell function $[26,27]$.

In addition to body fat percentage, MUAC has a strong correlation with BMI [16] therefore it can be used instead of BMI as a much simpler, cheaper anthropometric measurement, which does not change significantly during pregnancy. Hence, it may be a better indicator of pregnancy body fat and nutrition status than BMI [28]. MUAC does not need mathematical calculations, additional equipment, and regular equipment standardization which are important considerations in limited resource settings [29]. Furthermore, MUAC is highly associated with GDM [30] which means that a woman with a MUAC beyond the normal value is at increased risk of GDM compared to the one with normal MUAC value.

The current study was conducted in Arusha District, which has a known high prevalence of T2DM (16.2\%) especially in urban (22.9\%) compared to rural (9.9\%) areas [31], although this variance may, in part, reflect undiagnosed and unmanaged HIP outside the urban centres. This situation led to the need to determine the 
prevalence of HIP and its associated risk factors especially the less explored body fat percentage for possible interventions to prevent short- and long-term adverse effects to the mother and her newborn.

\section{Methods}

A cross-sectional study was conducted in urban areas of Arusha District between March and December of 2018. The study involved pregnant women attending antenatal clinics at Ngarenaro and Kaloleni Health Centers in Arusha District. The two centers were purposively selected due to their central location and large numbers of pregnant women (on average 40-100 per day) accessing Ante-Natal Care (ANC) services from across the District, thereby representing the demographics of this predominantly urban patient population. The study included women with gestational ages between 24 and 36 weeks anticipating delivery at one of the participating centers. Pregnant women with previously diagnosed diabetes and selected conditions, such as sickle-cell anemia or cancer, were excluded from the study. The aim, procedure, benefits, and negative effects of the study were explained to all enrolled women agreeing to participate and signed informed consents. The study was approved by the Tanzania National Institute of Medical Research (NIMR) with a reference number NIMR/HQ/R.8a/ Vol.IX/2694.

The eligible women were selected with assistance of the nurse in-charge resulting in a total of 468 women being involved in the study. Sample size was determined in accordance with the formula for prevalence studies [32]. Due to limited large-scale data on the prevalence of HIP in Tanzania, 50\% was used as prevalence in the formula for maximum reality [33] with an assumed attrition rate of $20 \%$. Random sampling using a table of numbers was used to select women to participate in the study and due to the high number of pregnant women attending ANC in the areas, 12 women were assessed per day. All participants $(100 \%, n=468)$ completed fasting blood glucose tests and face-to-face interviews using structured questionnaires. In addition, nearly all $(97.8 \%, n=446)$ of the participating women completed Oral Glucose Tolerance Test (OGTT) procedures.

\section{Assessment of demographic characteristics and selected risk factors for HIP}

Recalled information respecting weight before pregnancy, first generation family history of T2DM, previous history of GDM, symptoms of T2DM, and previous delivery of babies weighing $\geq 4 \mathrm{~kg}$ at birth were collected through face-to-face interviews using a structured questionnaire. Other maternal characteristics, such as age, perinatal and prenatal death, gravidity, education level, occupation, marital status, and weight during the first pre-natal visit, were obtained from the participants' ANC records.

\section{Laboratory tests for HIP}

Women were required to fast overnight before capillary blood was taken using a finger prick with a sterile lancet after cleaning the site with an antiseptic alcohol swab. Fasting blood glucose and $2 \mathrm{~h}$ OGTT following the consumption of anhydrous glucose of $75 \mathrm{~g}$ dissolved in 300 $\mathrm{ml}$ of water [3, 34] were measured using Gluco-plus ${ }^{\mathrm{mw}}$ (Glucoplus Inc. 2323 Halpern, Ville St. Laurent, Quebec, Canada). The capillary plasma glucose values obtained were converted into venous plasma glucose using the regression equation developed for diabetes screening in the low resource areas where venous blood is challenging [35]. Women whose fasting blood glucose levels were $\geq 5.1 \mathrm{mmol} / \mathrm{L}$ were requested to return the next day for another fasting glucose test. Women were classified as having HIP if they met the criteria for DIP and GDM which is fasting plasma glucose $(5.1-6.9 \mathrm{mmol} / \mathrm{l}$ (92$125 \mathrm{mg} / \mathrm{dl})$, or a 2 -h plasma glucose $(8.5-11.0 \mathrm{mmol} / \mathrm{l}$ (153-199 mg/dl) following a 75-g oral glucose load. The 1-h OGTT was not considered because there are no established criteria for the diagnosis of diabetes based on the 1 - $h$ post-load value and one reading is enough. Hence a single blood draw after $2 \mathrm{~h}$ is more reasonable than after every 1 hour [3]. In addition, DIP was classified by fasting plasma glucose $\geq 7.0 \mathrm{mmol} / \mathrm{l}(126 \mathrm{mg} / \mathrm{dl})$ and/or 2-h plasma glucose $\geq 11.1 \mathrm{mmol} / \mathrm{l}(200 \mathrm{mg} / \mathrm{dl})$ following a $75 \mathrm{~g}$ oral glucose load [34]. Furthermore, all women identified with HIP were referred to see the doctor for further actions.

\section{Anthropometric assessments}

Mid-upper arm circumference (MUAC) was measured using a non-stretchable tape and women were categorized as normal with a MUAC of $<28 \mathrm{~cm}$ and overweight with MUAC $\geq 28 \mathrm{~cm}$. Mid upper arm circumference was used to supplement BMI due to its relative stability during the course of pregnancy and high correlation with pre-pregnancy BMI, making it a better indicator of pre-pregnancy body fat and nutrition status than the BMI $[16,36]$. Weight was measured with minimal clothing and without shoes using a digital bathroom weighing scale (SECA-Germany), placed on a flat surface and recorded to the nearest $0.1 \mathrm{~kg}$. Body fat percent was determined using a bioelectric impedance analyzer (Tanita TBF 105 Fat Analyzer ${ }^{\mathrm{rw}}$ ) which includes adjustment for age, height, and sex. The body fat percentage was treated as a continuous variable and there are no established classification criteria for pregnancy. Blood pressure was measured using a GT-868UF Geratherm $^{\text {tm }}$ machine and women were classified using the blood pressure categories of systolic 130 to $139 \mathrm{mmHg}$ 
or diastolic 80 to $89 \mathrm{mmHg}$ for Stage 1 hypertension and systolic $\geq 140 \mathrm{mmHg}$ or diastolic $\geq 90 \mathrm{mmHg}$ for Stage 2 hypertension [37].

\section{Data analysis}

Data collected were analyzed using the Statistical Package for Social Science ${ }^{\mathrm{Tm}}$ (SPSS) Version 20 and descriptive statistics, such as frequency, mean and percentage, were obtained. Chi-square test was used for comparing the selected categorical variables between women with and those without HIP. Blood glucose levels were dichotomized, and univariate analysis was done for the variables associated with HIP to obtain crude odd ratios. Multiple logistic regression analysis explored whether different factors had significant association with HIP where the quantitative variables such as body fat percent, BMI and MUAC were treated as continuous variables. Statistical inference was based on 95\% confidence intervals (CIs) and significance at $p$ value $\leq 0.05$. Some factors were potential confounders, hence they were introduced into the model during the analysis, such as age, and gestational age. The variables with missing data (i.e., BMI) were analyzed by "pairwise" deletion where the statistical procedure used cases that contain some missing data. Hence, the entire case/respondent was not left out of subsequent analyses for elements on which data were complete. Other variables, which were missing due to mistakes in recording, were traced back from the participants as their phone numbers and other contacts were recorded. Other missing data were traced from ANC records available in the health center. Student's ttest was used to compare the means for HIP and nonHIP groups for continuous variables, such as mean OGTT and fasting glucose values.

\section{Results}

A total of 468 pregnant women participated in the study at Ngarenaro and Kaloleni Health Centers in Arusha, Tanzania. They were all black African by ethnicity. Most were married $(95.9 \%, n=459)$, and over half had attended primary school $(58.8 \%, n=275)$ and were selfemployed $(55.8 \%, n=261)$ primarily in small businesses earning an average income of $<250,000$ Tanzanian Shillings (TSH) per month (approximately 110 American dollars). The mean age of the women was 28 years ( $\mathrm{SD} \pm$ 5.84 ), of which $65.6 \%$ were $\geq 25$ years old. The mean gestational age at the start of ANC was 18 weeks (SD \pm $5.62)$ and 28.5 weeks $(S D \pm 3.82)$ at the beginning of this study where nearly two-thirds $(62.2 \%, n=354)$ were beyond 28 weeks gestation at time of entry to the study with $50.4 \%(n=236)$ reported as second or third gravidity (Table 1).

The mean self-reported pre-gestational weight was 67 $\mathrm{kg}(\mathrm{SD} \pm 12.5)$. This weight was used to determine pre-
Table 1 Demographic and selected maternal characteristics of pregnant women

\begin{tabular}{|c|c|c|c|}
\hline Respondent Variables & Frequency (n) & Percent (\%) & Mean $( \pm S D)$ \\
\hline \multicolumn{4}{|l|}{ Education levels } \\
\hline Never went to school & 8 & 1.7 & \\
\hline Primary level & 275 & 58.8 & \\
\hline Secondary level & 164 & 35.0 & \\
\hline College/University & 21 & 4.5 & \\
\hline \multicolumn{4}{|l|}{ Marital status } \\
\hline Single & 16 & 3.4 & \\
\hline Married or Cohabiting & 439 & 93.8 & \\
\hline Divorced/Separated & 13 & 2.8 & \\
\hline \multicolumn{4}{|l|}{ Occupational status } \\
\hline Formally employed & 46 & 9.8 & \\
\hline Self employed & 261 & 55.8 & \\
\hline Unemployed & 161 & 34.4 & \\
\hline \multicolumn{4}{|l|}{ Income per month (TSH) } \\
\hline$<250,000$ & 255 & 54.5 & \\
\hline $250,000-450,000$ & 33 & 7.1 & \\
\hline$\geq 500,000$ & 13 & 2.8 & \\
\hline I don't know & 167 & 35.7 & \\
\hline \multicolumn{4}{|l|}{ Age } \\
\hline$<25$ years & 164 & 35.0 & $28(S D \pm 5.84)$ \\
\hline$\geq 25$ years & 304 & 65.0 & \\
\hline \multicolumn{4}{|l|}{ Gestational age at first visit } \\
\hline$<12$ weeks & 57 & 12.2 & \\
\hline 12-24 weeks & 363 & 77.6 & $18(S D \pm 5.62)$ \\
\hline 25-36 weeks & 48 & 10.2 & \\
\hline \multicolumn{4}{|c|}{ Gestational age at study commencement } \\
\hline 24-28 weeks & 291 & 62.2 & $28(\mathrm{SD} \pm 3.82)$ \\
\hline$>28$ weeks & 117 & 37.8 & \\
\hline \multicolumn{4}{|l|}{ Gravidity } \\
\hline Prime & 142 & 30.3 & \\
\hline Second and third & 236 & 50.4 & $3(S D \pm 1.20)$ \\
\hline Fourth and above & 90 & 19.2 & \\
\hline
\end{tabular}

pregnancy BMI of the women in which $25.2 \%(n=60)$ were classified as overweight and $22.7 \%(n=54)$ as obese. The measured mean height was $159 \mathrm{~cm}(\mathrm{SD} \pm$ 6.3), body fat $33.7 \%(\mathrm{SD} \pm 7.2)$, and MUAC $27 \mathrm{~cm}(\mathrm{SD} \pm$ $3.8)$ in which $36.1 \%(n=164)$ had $\mathrm{MUAC} \geq 28 \mathrm{~cm}$ (Table 2).

All pregnant women who participated in the study $(100 \%, n=468)$ completed fasting blood glucose tests and $97.8 \%(n=446)$ underwent an OGTT. The prevalence of HIP was $16.2 \%$ (95\% CI: $13-19.9$ ) of which $3.2 \%$ $(n=15)$ had DIP and 13\% $(n=61)$ GDM using the WHO [3] criteria. Among the women assessed, 10.9\% 
Table 2 Anthropometric measurements of the pregnant

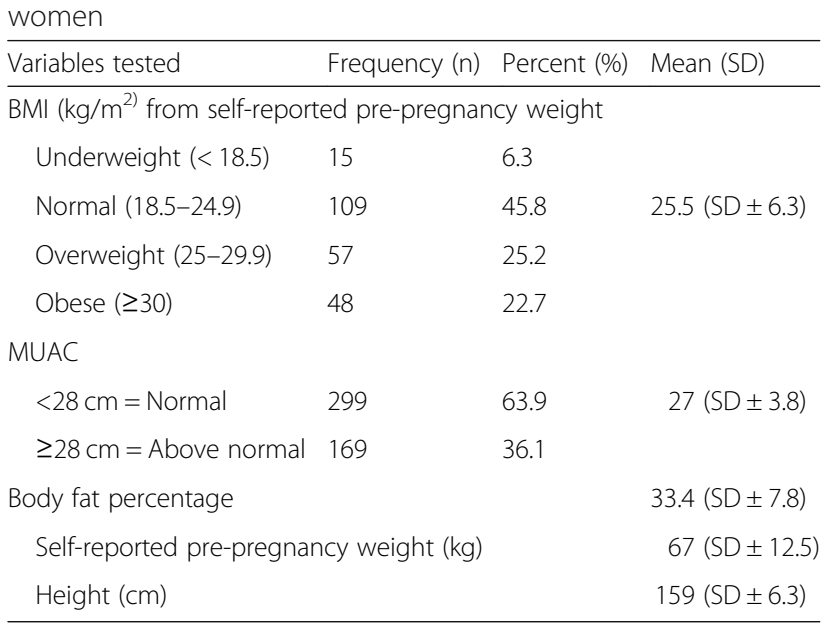

$(n=51)$ reported to have symptoms of T2DM, such as extreme tiredness, diaphoresis (excessive sweating), and polydipsia (excessive thirst) (Table 3 ).

The overall mean of fasting blood glucose was 4.5 $\mathrm{mmol} / \mathrm{L}(\mathrm{SD} \pm 1.3)$, with the HIP sub-group having a mean of $6.4 \mathrm{mmol} / \mathrm{L}(\mathrm{SD} \pm 1.5)$, yielding a significantly higher $(p<0.001)$ mean compared to the non-HIP group $(4.2 \mathrm{mmol} / \mathrm{L}, \mathrm{SD} \pm 0.9)$. The overall mean for OGTT was $5.5 \mathrm{mmol} / \mathrm{L}(\mathrm{SD} \pm 1.06)$ and was significantly higher $(p<$ $0.001)$ among the HIP $(8.3 \mathrm{mmol} / \mathrm{L}, \mathrm{SD} \pm 1.3)$ compared to the non-HIP group $(5.5 \mathrm{mmol} / \mathrm{L}, \mathrm{SD} \pm 0.1)$ (Table 4$)$.

The prevalence of HIP was significantly higher $(p<$ 0.000 ) among women with a family history of T2DM (44.9\% vs $10.5 \%, p<0.001) ;$ MUAC $\geq 28 \mathrm{~cm}(23.1 \%$ vs $12.4 \%, p=0.003)$; previous delivery of an infant $\geq 4 \mathrm{~kg}$ $(47.1 \%$ vs $4.4 \%, p<0.001)$; and symptoms of T2DM (49.1\% vs $12.2 \%, p<0.001)$. The observed prevalence of HIP did not differ significantly among women with histories of prenatal or perinatal death, high blood pressure, high maternal age, or smoking and alcohol intake habits $(p>0.05)$ (Table 5).

The selected risk factors were analyzed using multiple logistic regression analysis to determine their association

Table 3 Laboratory tests for glucose and protein among pregnant women

\begin{tabular}{lll}
\hline Variables Tested & Frequency $(\mathrm{n})$ & Percent $(\%)$ \\
\hline Pregnancy glycemia status & & \\
Normal & 392 & 83.8 \\
HIP & 76 & 16.2 \\
GDM & 61 & 13.0 \\
DIP & 15 & 3.2 \\
Having any symptoms of diabetes & \\
Yes & 51 & 10.9 \\
No & 417 & 89.1 \\
\hline
\end{tabular}

with HIP. A significant association was observed with increased body fat percentage (AOR 1.33, 95\% CI: $1.22-$ 1.44), family history of T2DM (AOR 6.95, 95\% CI: $3.11-$ 15.55) and previous delivery of babies $\geq 4 \mathrm{~kg}$ (AOR 2.3, 95\% CI: 1.00-5.28), and/or having any symptoms of T2DM (AOR 2.83, 95\% CI: 1.53-6.92) in the first model. The second model replaced body fat percentage with MUAC and the association remained consistently significant in all factors of the first model with addition of MUAC (AOR 1.2, 95\% CI: 1.09-1.32) (Table 6).

\section{Discussion}

The current study was carried out to determine the prevalence of HIP and influence of body fat percent and other risk factors on development of HIP among women in Arusha District. The overall prevalence of HIP was found to be $16.2 \%$, of which $3.2 \%$ had DIP and $13 \%$ GDM according to WHO criteria [3]. Gestational diabetes mellitus is not the only form of hyperglycemia which may first be detected during pregnancy as DIP is a more severe form of HIP in which diagnostic glucose levels are the same as those of non-pregnant adults [3]. Therefore, the prevalence of hyperglycemia in pregnancy in this study combined GDM and DIP as it is important to include pregnant women with pre-existing diabetes in designing interventions. Moreover, DIP increases the vulnerability to complications because of the degree of hyperglycemia and the uncertainty as to whether the onset of hyperglycemia was prior to pregnancy or it developed during pregnancy [2]. This study provides evidence for designing interventions like pre-pregnancy testing of blood glucose levels, emphasis on health education to improve health seeking behaviors among women of reproductive age. In Tanzania, due to limited resources, most women are not tested for glucose levels before pregnancy. It is therefore important that HIP is considered to ensure thorough glucose control before conception, throughout pregnancy and postpartum for prevention of diabetes in progressive pregnancies. Hence, including DIP and GDM together may strengthen the approach and allow recognition of general prevalence of hyperglycemia to open dialogue on future GDM approaches that align with global standards for all women in Tanzania. The observed prevalence of HIP may increase burden to the health system if no immediate actions are taken. The need exists to explore the associated modifiable risk factors including body fat to enhance self-care practices and prevent poor pregnancy outcomes as well as T2DM later in life. A similar study conducted in Tanzania using the same WHO [3] criteria reported that the prevalence of GDM was 19.5 and 3\% had DIP in Moshi Kilimanjaro Region which is higher than the current study [8]. The differences in 
Table 4 Mean blood glucose comparisons between women with and without HIP

\begin{tabular}{|c|c|c|c|c|}
\hline Variables Tested & Frequency(n) & Mean & SD & $P$-value \\
\hline \multicolumn{5}{|l|}{ Fasting blood glucose } \\
\hline General fasting blood glucose & 468 & 4.5 & \pm 1.3 & \\
\hline Normal $(<5.1 \mathrm{mmol} / \mathrm{L})$ & 397 & 4.2 & \pm 0.9 & $0.000^{*}$ \\
\hline HIP $(\geq 5.1 \mathrm{mmol} / \mathrm{L})$ & 71 & 6.4 & \pm 1.5 & \\
\hline \multicolumn{5}{|l|}{ OGTT } \\
\hline General OGTT values & 446 & 5.6 & \pm 1.06 & \\
\hline Normal $(<8.5 \mathrm{mmol} / \mathrm{L})$ & 436 & 5.5 & \pm 0.1 & $0.000^{*}$ \\
\hline Glucose intolerance ( $\geq 8.5 \mathrm{mmol} / \mathrm{L})$ & 10 & 8.3 & \pm 1.3 & \\
\hline
\end{tabular}

*significant

prevalence of hyperglycemia observed may be due to nature of the diets, cultural differences in food preparation, and care during pregnancy which needs further exploration. In addition, another similar study done in India supported our findings on the consideration of HIP in screening hyperglycemia during pregnancy and reported that, HIP was prevalent in $18.9 \%$ of the study population where by $16.3 \%$ had GDM and $2.6 \%$ DIP [38].

The prevalence of HIP in the present study was significantly associated with increased body fat percentage, family history of T2DM, previous delivery of $\geq 4 \mathrm{~kg}$ babies, and reported symptoms of T2DM. When body fat percentage was replaced by MUAC in the second model, increased in MUAC was independently associated with HIP. On other hand, BMI obtained from the recalled pre-pregnancy weight was not significantly associated with HIP even after been replaced for MUAC and/or body fat percentage in the models, making it a weak determinant of HIP. In this case, body fat percentage together with MUAC can be used instead of BMI as determinants of HIP due to their independent association with HIP. Moreover, the majority of the women in the current study could not recall their pre-pregnancy weight making it difficult to estimate their BMI. This finding is supported by Mwanri et al. [30] who found that BMI could not be estimated for most of the women, as they could not recall their pre-pregnancy weight. Another study reported that less than half of the mothers could recall their pre-gestational weight [39].

Although pre-gestational weight can be estimated with a recorded weight within 15 weeks of pregnancy [39], women in the current study started ANC with a mean gestational age of 18 weeks; hence, their pre-pregnancy weights were indeterminate. A similar study reported that, since most of the women appeared late to the ANC with a mean gestational age of 20 weeks, it was difficult to obtain pre-gestational weight [36]. Hence, information on changes in body fat content is required due to its independent association with HIP which is further supported in a previous report that the risk of GDM was independently associated with high body fat percent, similar to the findings in people with T2DM [23]. With these associations, it would be important to utilize these simple factors to identify pregnant women at risk for HIP so that prevention measures, such as lifestyle modifications, can be implemented to prevent poor pregnancy outcomes [40].

Women with a history of delivering babies $\geq 4 \mathrm{~kg}$ at birth were at twice the risk of GDM compared to their counterparts even after adjusting for body fat percentage, pre-pregnancy BMI, gestational age, and MUAC. This finding reveals how maternal health status is the determinant of health of the newborn. Another study found that a previous history of delivering a baby weighing $\geq 4 \mathrm{~kg}$ was an independent predictor of developing GDM [41]. This finding means that a woman with history of previous pregnancy, which resulted in a child with a high birth weight, is at an increased risk of GDM in progressive pregnancies [42].

The current study also reported that women with family history of diabetes were at almost 7 times greater risk of HIP compared to their non-affected counterparts meaning that HIP can be influenced by genetic predisposition and/or lifestyle practices, such as dietary and low physical activities. Another study showed that GDM is considered to result from interaction between genetic and environmental risk factors [43]. Pregnancy triggers a series of metabolic imbalances that lead to a diabetic state in women who are already genetically predisposed to develop diabetes [44]. Of note, GDM and T2DM share a similar genetic background [45] which might be a reason to why women with strong first-degree family history of T2DM are at high risk of HIP. Hence, genetic predispositions to T2DM or HIP should not be ignored. Other studies concur with the current report that family history of diabetes remained significantly associated with GDM even after adjustment for other co-variates $[37,46]$.

Nevertheless, some women with HIP reported having one or more symptoms of T2DM, such as extreme tiredness, diaphoresis (excessive sweating), and polydipsia 
Table 5 Comparison of selected characteristics between women with and without HIP

\begin{tabular}{|c|c|c|c|}
\hline Variable & With HIP & Without HIP & $P$-value \\
\hline \multicolumn{4}{|l|}{ MUAC } \\
\hline$<28 \mathrm{~cm}$ (Normal) & 37 (12.4\%) & $262(87.7 \%)$ & \multirow[t]{2}{*}{$0.003^{*}$} \\
\hline$\geq 28 \mathrm{~cm}$ (overweight/obese) & $39(23.1 \%)$ & $130(76.9 \%)$ & \\
\hline \multicolumn{4}{|l|}{ BMI pre-pregnancy } \\
\hline Underweight and Normal & 19 (15.3\%) & $105(84.7 \%)$ & \multirow[t]{2}{*}{0.251} \\
\hline Overweight and Obese & $24(21.1 \%)$ & $90(78.9 \%)$ & \\
\hline \multicolumn{4}{|l|}{ Family history of diabetes } \\
\hline Yes & $35(44.9 \%)$ & $43(55.1 \%)$ & \multirow[t]{2}{*}{$0.000^{*}$} \\
\hline No & $41(10.5 \%)$ & 349 (89.5\%) & \\
\hline \multicolumn{4}{|l|}{ Previous delivery to $\geq 4 \mathrm{~kg}$ baby } \\
\hline Yes & $48(47.1 \%)$ & $54(52.9 \%)$ & \multirow[t]{2}{*}{$0.000^{*}$} \\
\hline No & $10(4.4 \%)$ & $219(95.6 \%)$ & \\
\hline \multicolumn{4}{|l|}{ Mother's maternal age } \\
\hline$<25$ years & $24(14.4 \%)$ & $143(85.6 \%)$ & \multirow[t]{2}{*}{0.414} \\
\hline$\geq 25$ years & $52(17.3 \%)$ & $249(82.7 \%)$ & \\
\hline \multicolumn{4}{|l|}{ Symptoms of T2DM } \\
\hline Yes & $25(49.0 \%)$ & $26(51.0 \%)$ & \\
\hline No & $51(12.2 \%)$ & $366(87.8 \%)$ & $0.000^{*}$ \\
\hline \multicolumn{4}{|l|}{ Prenatal death } \\
\hline Yes & $10(15.9 \%)$ & $53(784.1 \%)$ & \multirow[t]{2}{*}{0.467} \\
\hline No & $48(17.9 \%)$ & $220(82.1 \%)$ & \\
\hline \multicolumn{4}{|l|}{ Perinatal death } \\
\hline Yes & $1(10.0 \%)$ & $9(90.0 \%)$ & \multirow[t]{2}{*}{0.538} \\
\hline No & $29(20.1 \%)$ & $115(79.9 \%)$ & \\
\hline \multicolumn{4}{|c|}{ Alcohol intake } \\
\hline Yes & $6(19.4 \%)$ & $25(80.6 \%)$ & \multirow[t]{3}{*}{0.665} \\
\hline Never & $63(15.5 \%)$ & $344(84.5 \%)$ & \\
\hline Stopped during pregnancy & $4(25.0 \%)$ & $12(75.0 \%)$ & \\
\hline \multicolumn{4}{|c|}{ Smoking } \\
\hline Never & $76(16.2 \%)$ & $390(83.7 \%)$ & 0.533 \\
\hline Stopped during pregnancy & $0(0.0 \%)$ & $2(100.0 \%)$ & \\
\hline
\end{tabular}

*Significant

(excessive thirst) and increased frequent urination. These symptoms were found to have a strong independent association with HIP even after adjusting for MUAC, BMI, gestational age and family history of T2DM. Considering the asymptomatic nature of HIP [19], these women may have pre-existing T2DM which was not diagnosed before pregnancy because, 3.2\% $(n=15)$ of the women were found to have high cut off points which indicated T2DM. This creates a need to promote pre-pregnancy preparation that include regular screening for diabetes before conception for earlier efforts to prevent
Table 6 Odd Ratios of select risk factors for hyperglycemia in pregnancy

Univariate analysis

\begin{tabular}{|c|c|c|}
\hline Risk factors & Crude OR $(95 \% \mathrm{Cl})$ & $P$-value \\
\hline $\begin{array}{l}\text { Body fat } \\
\text { percentage }\end{array}$ & $1.29(1.21-1.36)$ & $0.000^{*}$ \\
\hline MUAC & $1.16(1.09-1.24)$ & $0.000^{*}$ \\
\hline BMI & $1.01(0.99-1.03)$ & 0.294 \\
\hline \multicolumn{3}{|c|}{ Symptoms of T2DM } \\
\hline No & 1 & \\
\hline Yes & $6.9(3.7-12.86)$ & $0.000^{*}$ \\
\hline \multicolumn{3}{|c|}{ Family history of T2DM } \\
\hline No & 1 & \\
\hline Yes & $6.93(3.99-12.02)$ & $0.000^{*}$ \\
\hline \multicolumn{3}{|c|}{ Previous delivery of $\geq 4 \mathrm{~kg}$ baby } \\
\hline No & 1 & \\
\hline Yes & $5.9(3.13-11.03)$ & $0.000^{*}$ \\
\hline \multicolumn{3}{|c|}{ Preterm delivery } \\
\hline No & 1 & \\
\hline Yes & $1.2(0.366-3.826)$ & 0.779 \\
\hline
\end{tabular}

Multivariate analysis

Model 1

Model 2

$\begin{aligned} & \text { Risk factors } \text { Adjusted } \\ & \text { OR ( } 95 \%\end{aligned}$

Body fat $1.33(\mathrm{Cl}: 1.22-1.44) \quad 0.000^{*} \quad \mathrm{NA}$

percentage

MUAC NA

Symptoms of T2DM

No 1

$\begin{array}{lllll}\text { Yes } & 2.83(\mathrm{Cl}: 1.53-6.92) & 0.023^{*} & 3.66(\mathrm{Cl}: 1.64-8.18) & 0.002^{*}\end{array}$

Family history of T2DM

No 1

$\begin{array}{lllll}\text { Yes } & 6.95(\mathrm{Cl}: 3.11-15.55) & 0.000^{*} & 6.04(\mathrm{Cl}: 3.04-12.01) & 0.000 *\end{array}$

Previous delivery to $\geq 4 \mathrm{~kg}$ babies

\begin{tabular}{lllll} 
No & 1 & 1 & \\
Yes & $2.3(\mathrm{Cl}: 1.00-5.28)$ & $0.049^{*}$ & $3.5(\mathrm{Cl}: 1.71-7.36)$ & $0.001^{*}$ \\
\hline
\end{tabular}

The univariate analysis also included periterm death, maternal age, gestational age, and blood pressure with no significant association with HIP. Multivariate analysis included family history of Type 2 diabetes mellitus (T2DM), previous delivery of $\geq 4 \mathrm{~kg}$ babies, body fat percentage and MUAC in which body fat was replaced by MUAC in model 2.The abbreviation NA means not applicable in the particular model

the development of HIP. Hyperglycemia in pregnancy has few symptoms and should be diagnosed by screening during pregnancy [47]. Another study reported that overt symptoms of HIP are rare and may be difficult to distinguish from normal pregnancy symptoms creating a need for confirmatory OGTT [19]. Hyperglycemia in pregnancy can be influenced by first generation family history of T2DM and, when undiagnosed and 
unmanaged, can lead into recurrent HIP in subsequent pregnancies and/or T2DM later in life $[6,46]$. Hence, symptom clusters with other risk factors can be used for identification of women who need screening for HIP especially in low- and middle-income countries where universal screening is not possible.

\section{Limitation of the study}

Some data were collected based on participants' ability to recall. For example, BMI was based on recall data where almost half of the respondents could not report their pre-pregnancy weight leading to missing data; hence, interpretations on the rate of overweight and obesity need to be done carefully. In addition, GDM was tested by one out of two elevated glucose levels instead of one out of three values as recommended [3].

\section{Conclusions and recommendations}

The prevalence of HIP was observed to be high in urban areas of Arusha District and significantly associated with family history of T2DM, increased MUAC, body fat percentage, and having one or more symptoms of T2DM. The reported risk factors can be used to identify women at risk of HIP early enough for earlier interventions to be taken to prevent poor pregnancy outcomes especially in resource poor settings where universal screening is challenging. Modifiable risk factors, like body fat percentages for assessing nutrition status in pregnancy, need to be further explored to identify the proper methods for body fat estimation and develop criteria for classification in pregnancy. Prevention strategies for HIP need to be directed towards the knowledge and control of the risk factors reported in this study and others for promoting self-care before, during, and after pregnancy. This proactive approach can potentially reduce the impacts of non-modifiable risk factors, such as age and genetic predisposition in developing HIP.

\section{Abbreviations \\ ANC: Antenatal care; AOR: Adjusted Odd Ratios; BMI: Body Mass Index; Cl: Confidence Interval; GDM: Gestational Diabetes Mellitus; HIP: Hyperglycemia in Pregnancy; MUAC: Mid-Upper Arm Circumferences; OR: Odd Ratio; T2DM: Type 2 Diabetes Mellitus}

\section{Acknowledgements}

We are very thankful to the Nurses-in Charge Martha Sima from Ngarenaro ANC and Winfrida Masawe from Kaloleni ANC for their assistance with sampling, blood taking, and data collection arrangements. We also acknowledge our research assistants, Rafiki Julius and Janeth Ringo, for assisting in data collection.

\section{Authors' contributions}

This work was carried out in collaboration among 4 authors. Author SSM who is the corresponding author co-designed the study, Co-wrote the protocol, performed the literature search, data collection, entry and analysis as well as wrote the first manuscript draft. Author HDM, AWM and PP co-designed the study, co-wrote the protocol, conducted data analysis, co-supervised the project at all phases, and co-wrote the manuscript. All authors read and approved the final manuscript.

\section{Authors' information}

The correspondent author SSM is a PhD student at Nelson Mandela African Institution of Science and Technology-Tanzania. All other co-authors have PhDs and are supervising SSM in her PhD studies. In addition, the co-supervisor PP is a professor who is also a co-editor with BMC Nursing.

\section{Funding}

This article was possible due to the financial assistance for data collection from the World Bank through ACE-CREATES at Nelson Mandela African Institution of Science and Technology in Arusha-Tanzania. The funding agency had no influence on the study design, data collection, analysis, interpretation, and in writing the manuscript. The funder aimed to help the community.

\section{Availability of data and materials}

The datasets used and analyzed during the current study will be available on reasonable request to the corresponding author. This is because the data set contains other data that have not yet been analyzed as the study involves a prospective cohort part which is still going on in the area.

\section{Ethics approval and consent to participate}

The study was approved by the Tanzania National Institute for Medical Research (NIMR) committee with a reference number NIMR/HQ/R.8a/Nol. IX/ 2694. A written informed consent was obtained from the pregnant women after understanding the aim, advantages and disadvantages of the study. Confidentiality was assured by using numbers to represent their names.

\section{Consent for publication}

Not applicable.

\section{Competing interests}

The authors declare that they have no competing interests.

\section{Author details}

'Department of Food Biotechnology and Nutritional Sciences in School of Life Sciences, Nelson Mandela African Institution of Science and Technology, P. O. Box 477, Arusha, Tanzania. ${ }^{2}$ Department of Food Technology, Nutrition and Consumer Sciences, Sokoine University of Agriculture, Morogoro, Tanzania. ${ }^{3}$ College of Nursing, University of Saskatchewan, Saskatoon, Canada.

Received: 18 April 2019 Accepted: 19 August 2019

Published online: 28 August 2019

\section{References}

1. Negrato CA, Gomes MB. Historical facts of screening and diagnosing diabetes in pregnancy. Diabetol Metab Syndr. 2013;5(1):22.

2. Hod M, Kapur A, Sacks DA, Hadar E, Agarwal M, Di Renzo GC, et al. The International Federation of Gynecology and Obstetrics (FIGO) initiative on gestational diabetes mellitus: a pragmatic guide for diagnosis, management, and care. Int J Gynaecol Obstec. 2015;131(Suppl 3):S173-211.

3. World Health Organization. Diagnostic criteria and classification of hyperglycaemia first detected in pregnancy. Geneva: World Health Organization; 2013. http: //130.14.29.10/books/NBK169024. Accessed 20 June 2017

4. American Diabetes Association. Economic costs of diabetes in the U.S. in 2012. Diabetes Care. 2013;36:1033-46. https://doi.org/10.2337/dc12-2625 Accessed 02 July 2017.

5. Palani S, Joseph NM, Tegene Y, Zacharia A, Marew T. Gestational diabetes-a review. JGTPS. 2014;5(2):1673-83.

6. International Diabetes Federation. IDF Diabetes Atlas 6th edition. Brussels: International Diabetes Federation; 2013.

7. Macaulay S, Dunger DB, Norris SA. Gestational diabetes mellitus in Africa: a systematic review. PLoS One. 2014;9(6):e97871.

8. Njete HI, John B, Mlay P, Mahande MJ, Msuya SE. Prevalence, predictors and challenges of gestational diabetes mellitus screening among pregnant women in northern Tanzania. Tropical Med Int Health. 2017;23(2):236-42.

9. Ministry of Health, Community Development, Gender, Elderly and Children (MoHCD) [Tanzania Mainland], Ministry of Health (MoH) [Zanzibar], National Bereau of Statistics (NBS), Office of the Chief Government Statistician (OCGS), and ICF. Tanzania Demographic Health Survey and Malaria Indicator 
Survey (TDHS-MIS) 2015-16. Dar es Salaam and Rockville: MoHCDGEC, MoH, NBS, OCGS and ICF; 2016. p. 19.

10. Wendland EM, Torloni MR, Falavigna M, Trujillo J, Dode MA, Campos MA, et al. Gestational diabetes and pregnancy outcomes - a systematic review of the World Health Organization (WHO) and the International Association of Diabetes in pregnancy study groups (IADPSG) diagnostic criteria. BMC Pregnancy Childbirth. 2012;12(1):23.

11. Imoh LC, Ogunkeye OO, Isichei CO, Gadzama AA, Ekwempu CC. Combining the IADPSG criteria with the WHO diagnostic criteria for gestational diabetes mellitus optimizes predictability of adverse pregnancy outcome. Trop J Obstet Gynaecol. 2016;33:185-9.

12. Larijani B, Hossein-nezhad A, Rizvi SW, Munir S, Vassigh AR. Cost analysis of different screening strategies for gestational diabetes mellitus. Endocr Pract. 2003;9:504-9.

13. Jensen DM, Ovesen P, Beck-Nielsen H, Mølsted-Pedersen L, Sørensen B, Vinter $C$, et al. Gestational weight gain and pregnancy outcomes in 481 obese glucose-tolerant women in Denmark. Diabetes Care. 2005;28:2118-22.

14. Ay L, Knuithof CJ, Bakker R, Steegers EA, Witteman JC, Moll HA, et al. Maternal anthropometrics are associated with fetal size in different periods of pregnancy and at birth: the generation R study. BJOG. 2009;1 16:953-63.

15. Reilly JJ, Armstrong J, Dorosty AR, Emmett PM, Ness A, Rogers I, et al. Early life risk factors for obesity in childhood: cohort study. BMJ. 2005;330:1357-9.

16. Fakier A, Petro G, Fawcus S. Mid-upper arm circumference: a surrogate for body mass index in pregnant women. S Afr Med J. 2017;107(7):606-10.

17. Kotnik KZ, Golja P. Changes in body composition of university students in a country in socio-economic transition. Anthropol Anz. 2012;69:261-71.

18. Berggren EK, Groh-wargo S, Presley L, Hauguel-de mouzon S, Catalano PM. Maternal fat, but not lean, mass is increased among overweight/obese women with excess gestational weight gain. Am J Obstet Gynecol. 2016; 214(6):745.e1-5.

19. American Diabetes Association. Diagnosis and classification of diabetes mellitus. Diabetes Care. 2010;33(Suppl 1):S62-9.

20. Ravikumar B, Carey PE, Snaar JE, Deelchand DK, Cook DB, Neely RD, et al. Real-time assessment of postprandial fat storage in liver and skeletal muscle in health and type 2 diabetes. AJP-Endocrinol Metab. 2005;288(4):E789-97.

21. Weyer C, Foley JE, Bogardus C, Tataranni PA, Pratley RE. Enlarged subcutaneous abdominal adipocyte size, but not obesity itself, predicts type II diabetes independent of insulin resistance. Diabetologia. 2000;43(12):1498-506.

22. Qing X, Ying GZ, Ming LL, Lu W, Qian Z, Yue T, et al. The association of maternal body composition and dietary intake with the risk of gestational diabetes mellitus during the second trimester in a cohort of Chinese pregnant women. Biomed Environ Sci. 2016;29(1):1-11.

23. Iqbal R, Rafique G, Badruddin S, Qureshi R, Cue R, Gray-Donald K. Increased body fat percentage and physical inactivity are independent predictors of gestational diabetes mellitus in south Asian women. Eur J Clin Nutr. 2007; 61(6):736-42.

24. Kim SY, Saraiva C, Curtis M, Wilson HG, Troyan J, England L. Fraction of gestational diabetes mellitus attributable to overweight and obesity by race / ethnicity, California 2007-2009. Am J Public Health. 2013;103(10):e65-72.

25. Lear SA, Humphries KH, Kohli S, Chockalingam A, Frohlich JJ, Birmingham CL. Visceral adipose tissue accumulation differs according to ethnic background: results of the multicultural community health assessment trial (M-CHAT). Am J Clin Nutr. 2007:86(2):353-9.

26. Khoo CM, Sairazi S, Taslim S, Gardner D, Wu Y, Lee J, et al. Ethnicity modifies the relationships and adiponectin with obesity in a multiethnic Asian population. Diabetes Care. 2011;34:1120-6.

27. Lekva T, Bollerslev J, Godang K, Cecilie M, Roland P, Friis CM, et al. B-cell dysfunction in women with previous gestational diabetes is associated with visceral adipose tissue distribution. Eur J Endocrinol. 2015;173(1):63-70.

28. López LB, Calvo EB, Poy MS, del Valle Balmaceda Y, Cámera K. Changes in skinfolds and mid-upper arm circumference during pregnancy in argentine women. Matern Child Nutr. 2011;7(3):253-62.

29. Okereke CE, Anyaehie UB, Dim CC, lyare EE, Nwagha UI. Evaluation of some anthropometric indices for the diagnosis of obesity in pregnancy in Nigeria: a cross-sectional study. Afr Health Sci. 2013;13(4):1034-40.

30. Mwanri AW, Kinabo J, Ramaiya K, Feskens EJM. Prevalence of gestational diabetes mellitus in urban and rural Tanzania. Diabetes Res Clin Pract. 2014; 103(1):71-8.

31. Masaki S, Ngoye A, Petrucka P, Buza J. Type 2 diabetes prevalence and risk factors of urban Maasai in Arusha municipality and rural Maasai in Ngorongoro crater. JALSI. 2015;3(4):157-68.
32. Daniel WW. Biostatistics: A Foundation for analysis in the health sciences. 7th ed. New York: R Wiley; 1999. xiv +755. ISBN 0-471-16386-4

33. Macfarlane SB. Conducting a descriptive survey: 2.Choosing a sampling strategy. Trop Dr. 1997;27(1):14-21.

34. World Health Organization. Definition and diagnosis of diabetes mellitus and intermediate hyperglycemia: report of a WHO/IDF consultation, vol. 50. Geneva: World Health Organization; 2006. https://doi.org/ISBN9241594934. Accessed 15 May 2017

35. Bhavadharini B, Mohanraj M, Kumar M. Use of capillary blood glucose for screening for gestational diabetes mellitus in resource-constrained settings. Acta Diabetol. 2016;53:91-7. https://doi.org/10.1007/s00592-015-0761-9 Accessed 20 Mar 2017

36. Gale CR, Javaid MK, Robinson SM, Law CM, Godfrey KM, Cooper C. Maternal size inpregnancy and body composition in children. J Clin Endocrinol Metab. 2007:92(10):3904-11.

37. Whelton PK, Carey RM, Aronow WS, Casey DE, Collins K, Himmelfarb CD, et al. 2017 ACC/AHA/AAPA/ABC/ACPM/AGS/APhA/ASH/ASPC/NMA/PCNA guideline for the prevention, detection, evaluation, and management of high blood pressure in adults: a report of the American College of Cardiology/American Heart Association task force on clinical practice guidelines. J Am Coll Cardiol. 2018;71(19):e127-248.

38. Nielsen KK, Damm P, Kapur A, Balaji V, Balaji MS, Seshiah V, Bygbjerg IC. Risk factors for hyperglycaemia in pregnancy in Tamil Nadu, India. PloS One. 2016:11(3):e0151311.

39. Saldana TM, Siega-Riz AM, Adair LS. Effect of macronutrient intake on the development of glucose intolerance during pregnancy. Am J Clin Nutr. 2004;79:479-86.

40. Forsbach-Sanchez G, Tamez-Perez HE, Vazquez-Lara J. Diabetes and pregnancy. Arch Med Res. 2005;36:291-9.

41. Adam S, Rheeder P. Selective screening strategies for gestational diabetes: a prospective cohort observational ttudy. J Diabetes Res. 2017;107(6):523-7.

42. Ross G. Gestational diabetes. Aust Fam Physician. 2006;35(6):392-6.

43. Shaat N, Groop L. Genetics of gestational diabetes mellitus. Curr Med Chem. 2007;14(5):569-83.

44. Reece EA, Leguizamon G, Wiznitzer A. Gestational diabetes: the need for a common ground. Lancet. 2009;373:1789-97.

45. Kwak SH, Kim SH, Cho YM, Go MJ, Cho YS, Choi SH, et al. A genome-wide association study of gestational diabetes mellitus in Korean women. Diabetes. 2012;61(2):531-41.

46. Leng J, Shao P, Zhang C, Tian H, Zhang F, Zhang S, Yang X. Prevalence of gestational diabetes mellitus and its risk factors in Chinese pregnant women: a prospective population-based study in Tianjin, China. PLoS One. 2015:10(3):1-12.

47. Al-Noaemi MC, Shalaye MHF. In: Radenkovic M, editor. Pathophysiology of gestational diabetes mellitus: The past, the present and the future, gestational diabetes; 2011. ISBN: 978-953-307-581-5. Intech. https://www.intechopen com/books/gestational-diabetes/pathophysiology-of-gestational-diabetesmellitus-the-past-the-present -and-the-future. Accessed 25 Mar 2017.

\section{Publisher's Note}

Springer Nature remains neutral with regard to jurisdictional claims in published maps and institutional affiliations.

Ready to submit your research? Choose BMC and benefit from

- fast, convenient online submission

- thorough peer review by experienced researchers in your field

- rapid publication on acceptance

- support for research data, including large and complex data types

- gold Open Access which fosters wider collaboration and increased citations

- maximum visibility for your research: over $100 \mathrm{M}$ website views per year

At $\mathrm{BMC}$, research is always in progress.

Learn more biomedcentral.com/submissions 